\title{
Her2 positive subtype and breast cancer brain metastasis: any effect of anti-Her 2 targeted therapy?
}

\author{
Kadri Altundag ${ }^{1}$ (D)
}

Received: 8 July 2017 / Accepted: 9 September 2017 / Published online: 12 September 2017

(C) Springer Science+Business Media, LLC 2017

To the Editor,

I want to congratulate Saraf and their colleagues [1] for their study. They retrospectively reviewed all breast cancer brain metastasis (BCBM) patients treated with brain radiotherapy from 1997 to 2015 . They reported that patients with advanced high stage and triple negative breast cancer develop brain metastases significantly earlier. Interestingly, patients with Her2 positive subtype that did have documented anti-Her2 targeted therapy were excluded from the study. From this perspective, significant number of HER2 positive breast cancer patients who develop BCBM were eligible for the current study since they received anti-Her2 therapy as adjuvant and/or metastatic treatment. However, addition of anti-Her2 treatment at adjuvant or metastatic setting might delay BCBM. The efficacy of anti-Her2 therapy to control systemic disease for longer periods of time has exposed the ability of the Her2-positive breast cancer cells to develop BCBM later. In a retrospective study, patients with HER2-positive disease treated with trastuzumab had longer times to development of and better survival from BCBM compared with patients with Her2-positive disease who had never received trastuzumab [2]. Furthermore, In CLEOPATRA trial, where patients with Her2-positive first line metastatic breast cancer experienced significant improvements in progression-free and overall survival with pertuzumab, trastuzumab and docetaxel compared with placebo, trastuzumab and docetaxel [3]. In this trial, an exploratory analysis of the incidence and time to development of
BCBM as first site of disease progression, also showed that the incidence was similar between the two arms, however the time to development of BCBM was significantly prolonged in the pertuzumab arm from 11.9 to 1 months $(\mathrm{P}=0.0049)$. Therefore, interpretation of results of the patients with Her2 positive subtype in the current study should be evaluated in caution.

\section{Compliance with ethical standards}

Conflict of interest The author indicated no potential conflicts of interest.

\section{References}

1. Saraf A, Grubb CS, Hwang ME, Tai CH, Wu CC, Jani A, Lapa ME, Andrews JIS, Vanderkelen S, Isaacson SR, Sonabend AM, Sheth SA, McKhann GM, Sisti MB, Bruce JN, Cheng SK, Connolly EP, Wang TJC (2017) Breast cancer subtype and stage are prognostic of time from breast cancer diagnosis to brain metastasis development. J Neurooncol. doi:10.1007/s11060-017-2549-y

2. Dawood S, Broglio K, Esteva FJ, Ibrahim NK, Kau SW, Islam R, Aldape KD, Yu TK, Hortobagyi GN, Gonzalez-Angulo AM (2008) Defining prognosis for women with breast cancer and CNS metastases by HER2 status. Ann Oncol 19:1242-1248. doi:10.1093/annonc/mdn036

3. Swain SM, Baselga J, Miles D, Im YH, Quah C, Lee LF, Cortés J (2014) Incidence of central nervous system metastases in patients with HER2-positive metastatic breast cancer treated with pertuzumab, trastuzumab, and docetaxel: results from the randomized phase III study CLEOPATRA. Ann Oncol 25:1116-1121. doi:10.1093/annonc/mdu133
Kadri Altundag

altundag66@yahoo.com

1 MKA Breast Cancer Clinic, Tepe Prime, Cankaya, 06800 Ankara, Turkey 